Synthesis of Mesostructured Copper Sulfide by Cation Exchange and Liquid Crystal Templating

C. R. Lubeck, F. M. Doyle, A. E. Gash, J. H. Satcher, T.Y.J. Han

August 16, 2005

Advanced Materials 
This document was prepared as an account of work sponsored by an agency of the United States Government. Neither the United States Government nor the University of California nor any of their employees, makes any warranty, express or implied, or assumes any legal liability or responsibility for the accuracy, completeness, or usefulness of any information, apparatus, product, or process disclosed, or represents that its use would not infringe privately owned rights. Reference herein to any specific commercial product, process, or service by trade name, trademark, manufacturer, or otherwise, does not necessarily constitute or imply its endorsement, recommendation, or favoring by the United States Government or the University of California. The views and opinions of authors expressed herein do not necessarily state or reflect those of the United States Government or the University of California, and shall not be used for advertising or product endorsement purposes. 


\section{Synthesis of mesostructured copper sulfide by cation exchange and liquid crystal templating}

Christopher R. Lubeck ${ }^{1,2}$, Fiona M. Doyle ${ }^{2}$, Alexander E. Gash ${ }^{1}$, Joe H. Satcher Jr. ${ }^{1}$ and T. Yong-Jin $\operatorname{Han}^{1 *}$

${ }^{1}$ Chemistry and Materials Science Directorate, Lawrence Livermore National Laboratory, Livermore, CA 94550

${ }^{2}$ Department of Material Science and Engineering, University of California, Berkeley, CA 94720

*To whom correspondence should be addressed. Email: han5@1lnl.gov Fax: 925-4223160

** Authors would like to thank Jonathan R.I. Lee for helpful discussions and Jeffery Tok for the use of UV-Vis spectrometer. C.R.L would like to acknowledge the Student Employee Graduate Research Fellowship Program (SEGRF) at LLNL for financial support. This work was performed under the auspices of the U.S. Department of Energy by the Univeristy of California, Lawrence Livermore National Laboratory under contract No. W-7405-ENG-48. 
The development of synthetic pathways to yield advanced functional materials is an important aspect of materials science. In particular, the ability to control and manipulate the chemical composition and structure of inorganic nanomaterials is highly desirable. Two synthetic approaches which show great promise for producing the next generation of functional inorganic nanomaterials are i) templating of supramolecular assemblies ${ }^{[1]}$ and ii) ion exchange within nanostructured inorganic solids to manipulate chemical composition. ${ }^{[2-4]}$ Templating of supramolecular assemblies of surfactants and amphiphilic polymers has already proven to be a powerful technique in synthesizing various inorganic structures. Namely, numerous examples of mesostructured metal oxides $\left(\mathrm{SiO}_{2}, \mathrm{TiO}_{2}\right.$, $\mathrm{WO}_{3}$, etc.) have been synthesized by templating the liquid crystalline phases of amphiphilic polymers and surfactants (i.e. vesicles, 2D and 3D hexagonal and cubic phases, etc.) with inorganic precursors, resulting in the formation of highly ordered inorganic-organic hybrid materials. ${ }^{[5-10]}$ Although the templating of supramolecular assemblies has been successful in generating highly ordered mesostructured metal oxides, there are only a few examples of non-oxidic mesostructured inorganic materials. ${ }^{[11-17]}$ The recent developments of ion exchange within nanoparticles offer a promising approach to generating novel nanostructured inorganic materials with unique chemical compositions. Konenkamp et al. ${ }^{[2]}$ and Alivisatos et al. ${ }^{[4]}$ have successfully utilized the ion exchange methods to fully transform the chemical composition of simple nanostructured inorganic materials while retaining their shapes. Although the exact mechanism by which the ions exchange while retaining the overall structure is still unclear, this approach combined with templating of supramolecular assemblies can provide a potent technique for obtaining highly ordered inorganic materials with unique 
structures and chemical compositions. Herein, we describe for the first time, the successful synthesis of highly ordered, mesostructured $\mathrm{Cu}_{\mathrm{x}} \mathrm{S}$, by combining the templating of the supramolecular assemblies of non-ionic amphiphilic polymer method with the cation exchange method to transform mesostructured cadmium sulfide (CdS) into mesostructured copper sulfides $\left(\mathrm{CuS}, \mathrm{Cu}_{2} \mathrm{~S}\right)$.

Mesostructured CdS has been synthesized previously by direct templating of hexagonal mesophase of oligoethylene oxide oleyl ether $\left(\mathrm{C}_{18} \mathrm{H}_{35}\left(\mathrm{OCH}_{2} \mathrm{CH}_{2}\right)_{\mathrm{n}}-\mathrm{OH}, \mathrm{n} \sim 10\right.$, Brij 97) in $\mathrm{H}_{2} \mathrm{O} \cdot{ }^{[12,18]}$ Precipitation of $\mathrm{CdS}$ in the presence of self-assembled Brij 97 resulted in the formation of 2-dimensional hexagonally structured, inorganic-organic hybrid material that retained the long-range order of the original self-assembled amphiphilic polymer. The inorganic portion of these hybrid materials consisted of aggregates of $\mathrm{CdS}$ nanocrystals that are suitable for cation exchange with other mono and divalent metal ions. $\mathrm{Cu}^{2+}$ ion was chosen to replace $\mathrm{Cd}^{2+}$ ions in the $\mathrm{CdS}$ hybrid structure, since the formation of $\mathrm{Cu}_{\mathrm{x}} \mathrm{S}$ is thermodynamically favorable $\left(\Delta \mathrm{G}_{\mathrm{f}}<0\right)$ and highly ordered mesostructured $\mathrm{Cu}_{\mathrm{x}} \mathrm{S}$ has not been successfully synthesized by supramolecular templating method alone. Furthermore, nanoparticles of $\mathrm{Cu}_{\mathrm{x}} \mathrm{S}$ have shown to possess interesting optical properties, ${ }^{[3]}$ therefore, successful synthesis of mesostructured $\mathrm{Cu}_{\mathrm{x}} \mathrm{S}$ consisting of nanocrystals may lead to interesting properties and applications.

The transformation of hierarchically ordered mesostructured $\mathrm{CdS}$ to $\mathrm{Cu}_{\mathrm{x}} \mathrm{S}$ was initiated by addition of $\mathrm{Cu}^{2+}$ (aq) ions into finely dispersed mesostructured $\mathrm{CdS}$ powder in ethanolic solution and analyzed by transmission electron microscopy (TEM). A direct comparison between the as-made mesostructured $\mathrm{CdS}$ (figure 1a) and to the cation 
exchanged product (figure 1b) clearly show the similar channel structures and hexagonally ordered porous networks. According to TEM analysis of the mesostructured $\mathrm{Cu}_{\mathrm{x}} \mathrm{S}$ samples, the inorganic portion of the newly formed mesostructured hybrid material consisted of $4 \mathrm{~nm}$ thick walls separated by $2 \mathrm{~nm}$ cylindrical spaces, which were initially formed and occupied by the self-assembled organic polymers. Further analysis of the sample showed that the presence of the channels and the porous structures in the newly formed hybrid material were ubiquitous, similar to the original mesostructured CdS. The individual particles of the $\mathrm{Cu}_{\mathrm{x}} \mathrm{S}$ mesostructures ranged from $50 \mathrm{~nm}$ to $500 \mathrm{~nm}$ in diameter. The highly ordered mesostructures of the smaller particles were clearly evident, whereas the larger particles less clearly resolved, due to the random deposition of the samples onto the TEM grid and the thickness of the particles, thus preventing observation of their long-range order within a given sample. High-resolution TEM (HRTEM) analyses were performed on both mesostructured $\mathrm{CdS}$ and $\mathrm{Cu}_{\mathrm{x}} \mathrm{S}$ to obtain detailed information regarding the structure of the inorganic portion of the hybrid materials. HRTEM analysis showed (figure 1c, 1d) that the cation exchange process resulted in the transformation of crystalline $\mathrm{CdS}$ to crystalline $\mathrm{Cu}_{\mathrm{x}} \mathrm{S}$ in the inorganic portions of the mesostructures. Selected area electron diffraction (SAED) measurements of both samples (figure 1a, 1b insets) also confirmed that both were crystalline.

In order to confirm the chemical composition of the newly formed mesostructured hybrid materials, individual particles were analyzed by energy dispersive X-ray spectroscopy (EDS). Figure $2 \mathrm{a}$ and $2 \mathrm{~b}$ show the EDS spectra of the mesostructured materials before and after the cation exchange process. EDS spectra of the mesostructured $\mathrm{Cu}_{\mathrm{x}} \mathrm{S}$ (figure $2 \mathrm{~b}$ ) clearly show well defined $\mathrm{Cu} \mathrm{K} \alpha(8.04 \mathrm{keV}), \mathrm{L} \alpha(0.92$ 
$\mathrm{keV}$ ) peaks along with the sulfur $\mathrm{K} \alpha$ peak at $2.3 \mathrm{keV}$. More important, however, was the absence of cadmium $\mathrm{L} \alpha$ peaks at $3.1 \mathrm{keV}$ and $\mathrm{L} \beta$ at $3.3 \mathrm{keV}$ in the EDS analysis of the hexagonally ordered $\mathrm{Cu}_{\mathrm{x}} \mathrm{S}$ mesostructures, confirming the total exchange of cations during the transformation process from $\mathrm{CdS}$ to $\mathrm{Cu}_{\mathrm{x}} \mathrm{S}$. It is important to note that the $\mathrm{Cu}$ $\mathrm{K} \alpha$ and $\mathrm{K} \beta$ peaks observed in figure $2 \mathrm{a}$ are due to the copper grid used during the analysis. However, a clear distinction between the $\mathrm{Cu}_{\mathrm{x}} \mathrm{S}$ sample and copper grid can be made by comparing the $\mathrm{Cu} \mathrm{L}$ line in the EDS spectra which is much more prominent in figure 2b. X-ray fluorescence (XRF) measurements along with X-ray absorption spectroscopy (XAS) were also performed on mesostructured $\mathrm{Cu}_{\mathrm{x}} \mathrm{S}$ that corroborated the EDS results. ${ }^{[19]}$

The initial indication of successful cation exchange of $\mathrm{Cu}^{2+}$ for $\mathrm{Cd}^{2+}$ ions in the mesostructured $\mathrm{CdS}$ was an immediate color change upon addition of $\mathrm{Cu}^{2+}$ ions to the mesostructured materials in ethanolic solution. The shift in the absorption bands of the mesostructured materials during the transformation was monitored by UV-Vis spectrophotometery. The UV-Vis spectra of the as-made mesostructured CdS show strong absorption bands at $485 \mathrm{~nm}$ (figure 3a), due to the exciton transition within individual $\mathrm{CdS}$ nanocrystals. When $\mathrm{Cu}^{2+}$ ions were introduced to the as-made $\mathrm{CdS}$ samples, however, a dramatic blue shift was observed (figure 3b). The newly formed mesostructured $\mathrm{Cu}_{\mathrm{x}} \mathrm{S}$ shows a broad band with $\lambda_{\max }$ at $375 \mathrm{~nm}$, which, according to previously published results, ${ }^{[20,21]}$ is indicative of $\mathrm{Cu}_{2} \mathrm{~S}$ nanoparticle formation. It is interesting to note that we specifically observed an absorption band for $\mathrm{Cu}_{2} \mathrm{~S}$, when in fact $\mathrm{Cu}^{2+}$ ions were added to the mesostructured $\mathrm{CdS}$. It is well known that aqueous formation of copper sulfides is complex and can produce both $\mathrm{CuS}$ and $\mathrm{Cu}_{2} \mathrm{~S}$ depending 
on the reaction conditions. ${ }^{[22-24]}$ Therefore, it may be possible that we have a mixture of both $\mathrm{Cu}_{2} \mathrm{~S}$ and $\mathrm{CuS}$ nanoparticles, which we are currently investigating. The breadth of the peak at $375 \mathrm{~nm}$ can be attributed to the polydispersity of the $\mathrm{Cu}_{\mathrm{x}} \mathrm{S}$ nanocrystals within the mesostructures.

TGA analysis was also performed on both mesostructured $\mathrm{CdS}$ and $\mathrm{Cu}_{\mathrm{x}} \mathrm{S}$ materials to determine the concentration of the amphiphilic polymer within the hybrid materials. As seen in figure $4 \mathrm{a}$, weight loss from the mesostructured CdS occurs in two distinct stages. The initial weight loss of $7 \%$, which occurs from the onset, is attributed to the loss of water physisorbed on to the inorganic solids and the ethylene oxides moieties of the amphiphilic polymer. The second step of weight loss, which occurs between approximately $200{ }^{\circ} \mathrm{C}$ and $350{ }^{\circ} \mathrm{C}$, is due to decomposition of the amphiphilic polymer. The total weight change due to the amphiphilic polymer is approximately 15 $\%$. Although the initial concentration of the polymer during the synthesis of the mesostructured $\mathrm{CdS}$ is much greater, excess polymer, which did not part-take in the formation of the hybrid materials, is removed during the recovery process of the inorganic-organic composite materials in multiple rinsing cycles. Therefore, the remaining polymer component after the rinse cycles is thought to reside within the mesostructures occupying the void spaces in between the inorganic solids (i.e. channels and pores). The mesostructured $\mathrm{Cu}_{\mathrm{x}} \mathrm{S}$ materials were also subjected to the same TGA analysis. It can be seen in figure $4 \mathrm{~b}$ that the profile of the TGA curves for $\mathrm{Cu}_{\mathrm{x}} \mathrm{S}$ sample are similar to that of CdS sample. However, the total weight change due to water and the polymer in the $\mathrm{Cu}_{\mathrm{x}} \mathrm{S}$ materials is much lower $(\sim 5 \mathrm{wt} \%)$ than for the $\mathrm{CdS}$ sample. We attribute the differences in the overall weight loss between mesostructured $\mathrm{CdS}$ and $\mathrm{Cu}_{\mathrm{x}} \mathrm{S}$ 
materials to the loss of incorporated polymers during the cation exchange process, as well as during the recovery process of the newly formed $\mathrm{Cu}_{\mathrm{x}} \mathrm{S}$ materials. Although the presence of the amphiphilic polymer is critical in obtaining the mesostructured CdS, it appears that during the cation exchange process, the presence of the amphiphilic polymer is not required to retain the overall morphology. The ability to retain the mesostructures during the cation exchange process in the absence of the templating organic molecules once again reemphasizes the versatility of ion exchange method in transforming nanostructured inorganic materials.

In summary, a successful morphological transformation of ordered mesostructured $\mathrm{CdS}$ to $\mathrm{Cu}_{\mathrm{x}} \mathrm{S}$ was achieved for the first time. The precise mechanism of cation exchange in the mesostructured $\mathrm{CdS}$, while retaining their structure, is unknown at this time. Nonetheless, the overall integrity of the mesostructures is retained after the cation exchange process. The newly formed $\mathrm{Cu}_{2} \mathrm{~S}$ structures are composed of $4 \mathrm{~nm} \mathrm{Cu}_{2} \mathrm{~S}$ nanoparticles with no residual $\mathrm{CdS}$ structures present. The formation of $\mathrm{Cu}_{2} \mathrm{~S}$ nanoparticles in the mesostructured $\mathrm{Cu}_{2} \mathrm{~S}$ may have interesting optical and electronic properties, which we are currently investigating. This new method of material synthesis, which incorporates the versatility of supramolecular assembly templating techniques with the ion exchange method, provides a potent tool for fabricating highly ordered inorganic nanostructures, with various chemical compositions, which are otherwise difficult to synthesize. 


\section{Experimental}

Synthesis of mesostructured CdS

Mesostructured cadmium sulfide was synthesized according to procedures detailed in published literature. ${ }^{[18]}$ Typically, liquefied Brij 97 was added to a scintillation vial along with $0.50 \mathrm{ml}$ of $0.1 \mathrm{M} \mathrm{Cd}\left(\mathrm{NO}_{3}\right)_{2}$. The capped vial was then heated to $90{ }^{\circ} \mathrm{C}$ and shaken to yield a homogeneous mixture. Subsequently, the homogeneous mixture was allowed to cool to room temperature which resulted in formation of a clear gel. The uncapped scintillation vial was then transferred to an Erlenmeyer flask with inlet and outlet ports. The precipitation of mesostructured $\mathrm{CdS}$ was initiated by flowing hydrated $\mathrm{H}_{2} \mathrm{~S}$ gas to the Erlenmeyer flask containing the scintillation vial for $30 \mathrm{~min}$. The resulting mesostructured CdS gel was rinsed excessively in 50/50 vol \% solution of diethyl ether/ethanol and dispersed by sonication. The final product was recovered through centrifugation.

Synthesis of mesostructured $\mathrm{Cu}_{\mathrm{x}} \mathrm{S}$

The cation exchange process of mesostructured $\mathrm{CdS}$ to $\mathrm{Cu}_{\mathrm{x}} \mathrm{S}$ was initiated by adding dropwise aqueous copper sulfate solution $(270 \mathrm{mM})$ to a dispersion of mesostructured $\mathrm{CdS}$ in ethanolic solution (50mg CdS/Brij 97 in $10 \mathrm{~mL}$ ethanol, $27 \mathrm{mM}$ ) over a period of 5 minutes. The mixture was allowed to react and age at room temperature for a minimum of 3 hours. The resulting product was rinsed several times with ethanol/water mixture and recovered by centrifugation yielding a black/brown powder.

\section{References}

[1] J. Y. Ying, C. P. Mehnert, M. S. Wong, Angew. Chem., Int. Ed. 1999, 38, 56.

[2] L. Dloczik, R. Konenkamp, Nano Letters 2003, 3, 651.

[3] V. Klimov, P. H. Bolivar, H. Kurz, V. Karavanskii, V. Krasovskii, Y. Korkishko, Appl. Phys. Lett. 1995, 67, 653.

[4] D. H. Son, S. M. Hughes, Y. D. Yin, A. P. Alivisatos, Science 2004, 306, 1009.

[5] S. C. Laha, R. Ryoo, Chemical Communications 2003, 2138.

[6] Y. Sakamoto, T. W. Kim, R. Ryoo, O. Terasaki, Angew. Chem., Int. Ed. 2004, 43, 5231.

[7] P. D. Yang, T. Deng, D. Y. Zhao, P. Y. Feng, D. Pine, B. F. Chmelka, G. M. Whitesides, G. D. Stucky, Science 1998, 282, 2244.

[8] P. D. Yang, D. Y. Zhao, D. I. Margolese, B. F. Chmelka, G. D. Stucky, Nature 1998, 396, 152.

[9] Z. R. Zhang, T. J. Pinnavaia, J. Am. Chem. Soc. 2002, 124, 12294.

[10] B. Z. Tian, X. Y. Liu, Z. D. Zhang, B. Tu, D. Y. Zhao, J. Solid State Chem. 2002, $167,324$.

[11] G. S. Attard, P. N. Bartlett, N. R. B. Coleman, J. M. Elliott, J. R. Owen, J. H. Wang, Science 1997, 278, 838.

[12] P. V. Braun, P. Osenar, S. I. Stupp, Nature 1996, 380, 325.

[13] F. Gao, Q. Y. Lu, D. Y. Zhao, Adv. Mat. 2003, 15, 739.

[14] T. W. Kim, I. S. Park, R. Ryoo, Angew. Chem., Int. Ed. 2003, 42, 4375.

[15] K. K. Rangan, P. N. Trikalitis, C. Canlas, T. Bakas, D. P. Weliky, M. G. Kanatzidis, Nano Letters 2002, 2, 513. 
[16] P. N. Trikalitis, T. Bakas, M. G. Kanatzidis, J. Am. Chem. Soc. 2005, 127, 3910.

[17] P. N. Trikalitis, N. Ding, C. Malliakas, S. J. L. Billinge, M. G. Kanatzidis, J. Am. Chem. Soc. 2004, 126, 15326.

[18] P. V. Braun, P. Osenar, V. Tohver, S. B. Kennedy, S. I. Stupp, J. Am. Chem. Soc. 1999, 121, 7302.

[19] Further details on XRF and XAS measurements will be made available else where.

[20] S. K. Haram, A. R. Mahadeshwar, S. G. Dixit, J. Phys. Chem. 1996, 100, 5868.

[21] Z. P. Liu, D. Xu, J. B. Liang, J. M. Shen, S. Y. Zhang, Y. T. Qian, Journal Of Physical Chemistry B 2005, 109, 10699.

[22] R. H. Kore, J. S. Kulkami, S. K. Haram, Chem. Mater. 2001, 13, 1789.

[23] G. W. Luther, S. M. Theberge, T. F. Rozan, D. Rickard, C. C. Rowlands, A. Oldroyd, Environmental Science \& Technology 2002, 36, 394.

[24] E. J. Silvester, F. Grieser, B. A. Sexton, T. W. Healy, Langmuir 1991, 7, 2917. 


\section{Figure Captions}

Figure 1) TEM images of a) mesostructured CdS and selected area electron diffraction (inset), and b) mesostructured $\mathrm{Cu}_{\mathrm{x}} \mathrm{S}$ and selected area electron diffraction (inset). Energy dispersive X-ray spectra of mesostructured $\mathrm{CdS}$ and $\mathrm{Cu}_{\mathrm{x}} \mathrm{S}$ are shown in c) and d) respectively. TEM measurements were made on Philips FEG CM300, operating at $300 \mathrm{kV}$ using copper grid with lacey formvar. The scale bar $=20$ $\mathrm{nm}$.

Figure 2) UV-Vis absorption spectra of a) mesostructured CdS with $\lambda_{\max }=485 \mathrm{~nm}$ and b) mesostructured $\mathrm{Cu}_{\mathrm{x}} \mathrm{S}$ with $\lambda_{\max }=385 \mathrm{~nm}$. UV-Vis absorption measurements were made with PerkinElmer Lambda 25 Spectrometer.

Figure 3) TGA spectra of a) mesostructured $\mathrm{CdS}$ and b) mesostructured $\mathrm{Cu}_{\mathrm{x}} \mathrm{S}$ under nitrogen. TGA analyses were performed on Mettler TG50 thermobalance system at heating rate of $10^{\circ} \mathrm{C} / \mathrm{min}$. 
Figure 1

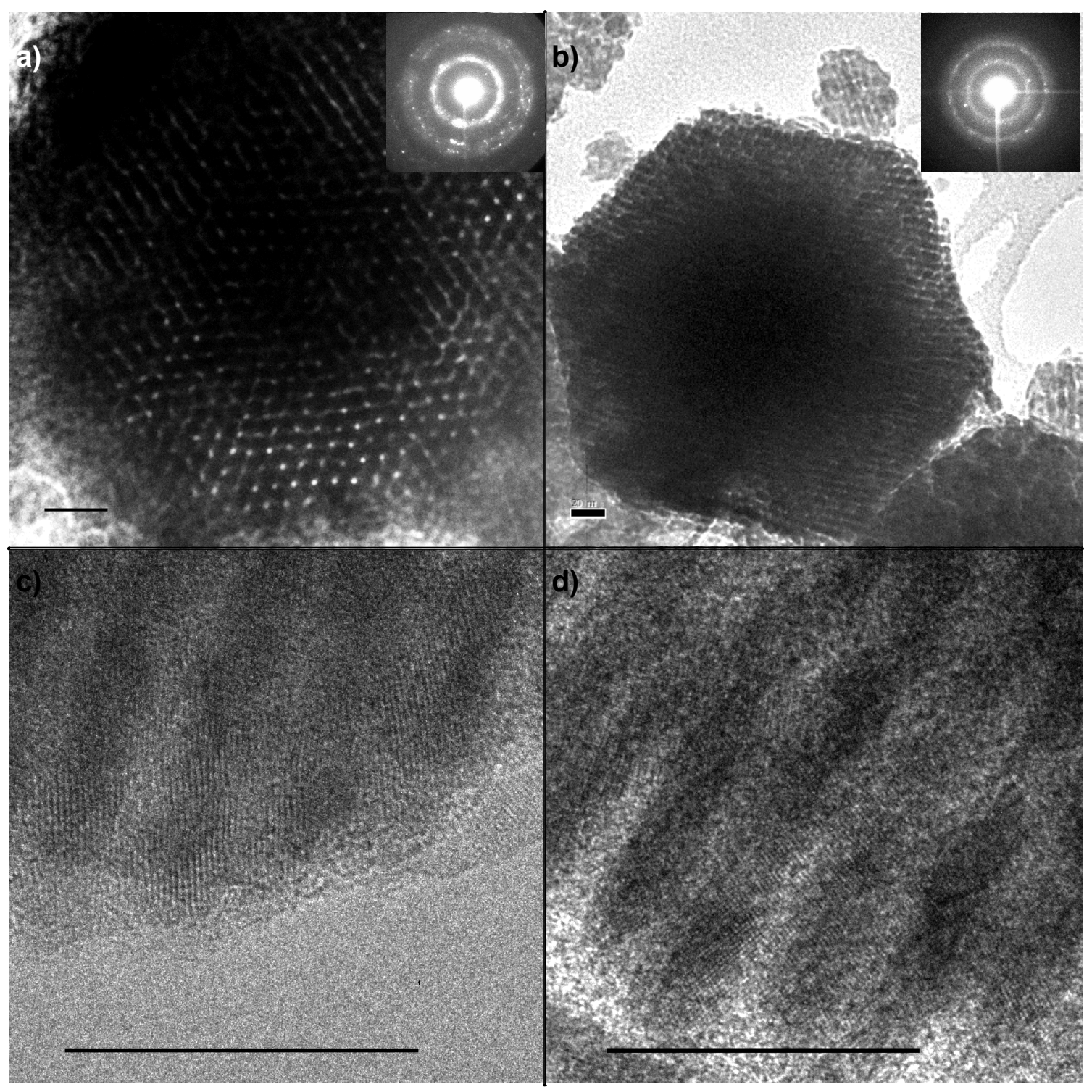


Figure 2




Figure 3

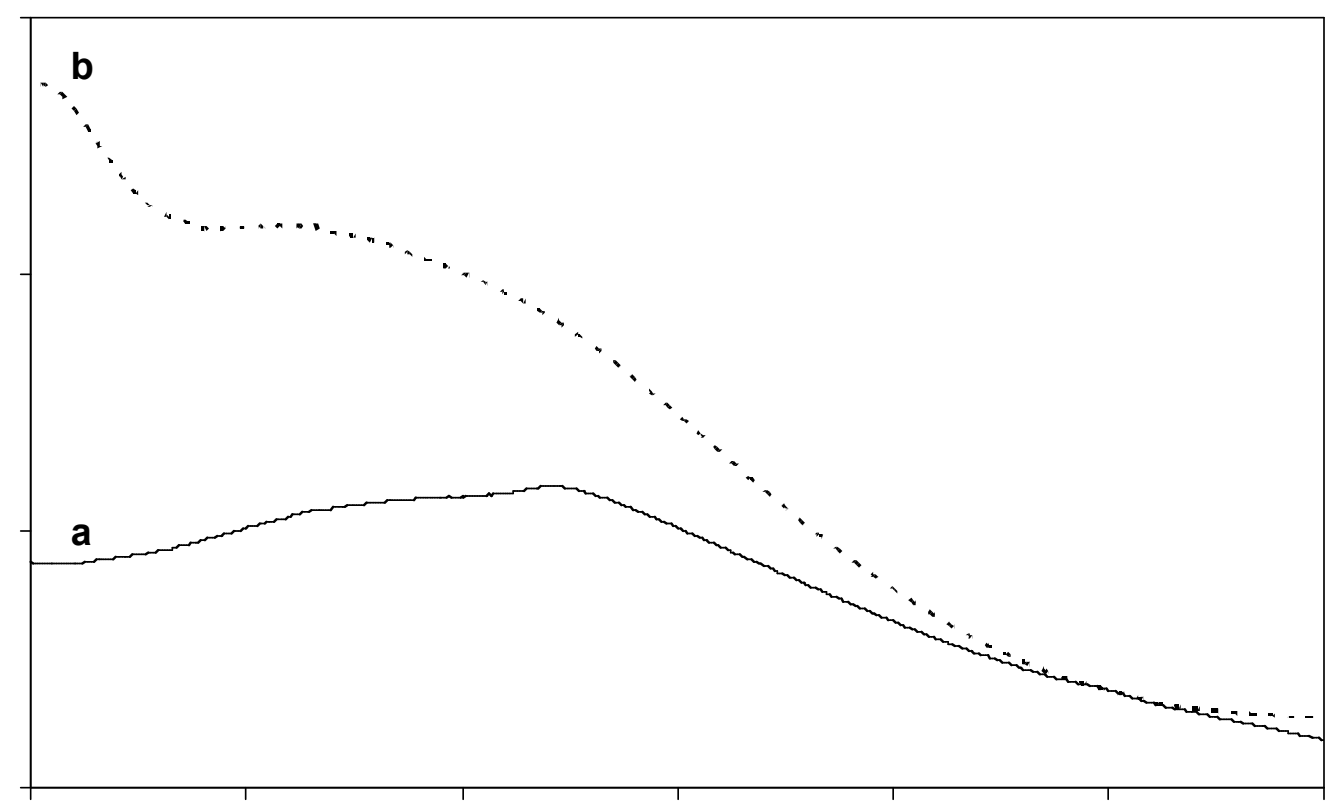


Figure 4

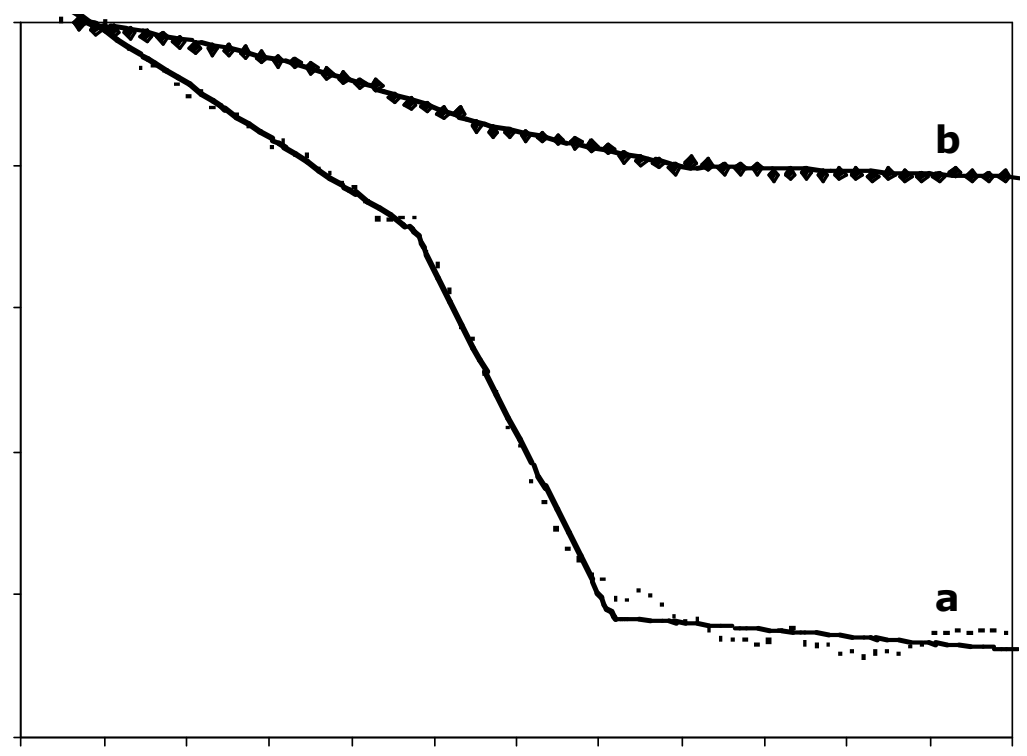

